\title{
Scales of Turbulent Eddies in a Compound Channel
}

\author{
Adam KOZIOŁ \\ Faculty of Civil and Environmental Engineering, \\ Warsaw University of Life Sciences, Warszawa, Poland \\ e-mails: adam_koziol@sggw.pl
}

\begin{abstract}
Experimental research was undertaken to investigate the changes in scales of turbulent eddies (macro- and microeddies) in a compound channel and the influence of rigid, emergent floodplain vegetation on scales of turbulent eddies. The results of eight tests for different roughness conditions (smooth bed, rough bed) and with a tree system on the floodplains from two earlier studies are presented. The increase of the channel roughness resulted in a decrease of longitudinal sizes of macroeddies in the whole channel. Trees on the floodplains resulted in disintegration of the sizes of macroeddies, making values of sizes more uniform. A more significant decreasing influence on sizes of macroeddies in the whole channel was exerted by an increase of the main channel sloping bank roughness, having a higher effect than a twofold decrease in the floodplain trees density. The microeddies' sizes are larger in the main channel centreline than on the floodplains and the smallest ones were present in the main channel/floodplain interface.
\end{abstract}

Key words: compound channel, eddies, emergent vegetation, floodplains.

\section{INTRODUCTION}

Natural rivers during flood events are often characterized by a compound cross-section and unsteady flow. In these channels, flood conditions lead to

Ownership: Institute of Geophysics, Polish Academy of Sciences;

(C) 2015 Kozioł. This is an open access article distributed under the Creative Commons

Attribution-NonCommercial-NoDerivs license,

http://creativecommons.org/licenses/by-nc-nd/3.0/. 
a complex, 3D flow situation with intensive mass and momentum exchange between the deep main channel and the shallow floodplains. This produces a transverse shear layer influencing the flow in both the main channel and the floodplains. The momentum transfer takes place not only by the bed generated turbulence but also by free shear turbulence and velocity fluctuations associated with perturbations in the secondary currents (Czernuszenko et al. 2007). The shape of the cross section varies and the roughness of the main channel and the floodplains is often different and the flow structure of a compound channel is usually very complex. The momentum transfer between the main channel and the floodplain generally enhances the discharge on the floodplain, decreasing it in the main channel and thus decreasing the total discharge capacity. The proper description of this so-called "interaction mechanism" is crucial for a reliable prediction of the flow field and related processes, such as flooding, spreading of pollutants, and transport of solids due to sedimentation and erosion. The structure of turbulence in such flows is extremely complex and many experimental works have been performed to investigate it (e.g., Knight and Shiono 1990, 1996, Knight et al. 1994, Shiono and Knight 1990, 1991, Tominaga et al. 1989). The presence of emergent riparian vegetation on river floodplains makes hydraulic processes even more complex. Vegetation in a compound channel results in an increase in a flow resistance as well changes of velocity distributions, water depth, and turbulent flow characteristics. Research on flow conditions in channels with flexible and rigid vegetation has been performed for a wide range of vegetation density changes: from a dense vegetation distribution to individual plants in a cross-section for both the submerged and emergent vegetation (Ben Meftah et al. 2006, Rowiński and Mazurczyk 2006, Yang et al. 2007, Nepf and Ghisalberti 2008, Sanjou et al. 2010, Terrier et al. 2010, Siniscalchi et al. 2012, Kubrak et al. 2013, Kozioł 2013).

The turbulence generation produces fluctuations of the flow velocity associated with big vortices, and the turbulent energy is transferred in an energy cascade to smaller-scale eddies until it is dissipated into heat by the molecular viscosity (Nezu and Nakagawa 1993). The largest eddies (macroeddies) are impermanent and disintegrate into structures of smaller sizes (microeddies), but simultaneously new, large structures are generated. As a result, the whole and continuous range of sizes of eddies exists in the flow. The scales of eddies in flows are crucial for determining sediment transport and deposition, bed formation, and other processes in rivers. Therefore, the turbulence structure in vegetated river sections has been in the focus of many studies (e.g., Nepf and Ghisalberti 2008).

This paper presents the analysis of an influence of channel roughness and floodplain trees on the longitudinal sizes of the macro- and microeddies, calculated based on the measurements of instantaneous, longitudinal water 
velocities in a compound channel from two previous experimental investigations. The main aim of this paper is an analysis of the longitudinal sizes of macro- and microeddies distributions in a channel of a compound crosssection, without and with the impact of floodplain trees.

\section{SCALES OF TURBULENT EDDIES}

The external scale of turbulence is determined by the sizes of macroeddies. Evaluation of sizes of macroeddies must be preceded by the determination of time-scales of macroeddies. To this end, autocorrelation functions $R(t)$ can be used for this evaluation. The functions exhibit very similar forms of decaying curves with an alteration of the domains of the positive and negative values. Basing on autocorrelation functions, Euler time-macroscales $T_{E}$ are derived according to Nikora et al. (1994):

$$
T_{E}=\int_{0}^{\infty} R(t) d t,
$$

which are a measure of the slowest changes in the turbulent flow caused by macroeddies. For a steady and uniform turbulent flow, when mean velocity in a given point significantly exceeds the velocity of fluctuations, there exists, according to the Taylor's hypothesis, a direct relationship of temporal and spatial Eulerian autocorrelation functions. Referring to Taylor's relationships between the spatial $L$ and temporal $T_{E}$ turbulence macroscale, the following formula for mean longitudinal sizes can be derived:

$$
L=U T_{E},
$$

where $U$ is the time-averaged point velocity. Most often the sizes of macroeddies are related to the water depths $h$ in an analysed measurement vertical for easier comparison.

The size of microeddies is a measure for the smallest size of eddies which are present in the turbulent flow of water. Kolmogoroff and Taylor proposed the spatial scale of microeddies (Nezu and Nakagawa 1993, Mazurczyk 2007). The Taylor's microscale depends both on the macroscopic motion by means of the fluctuating velocity and on dissipative characteristics, whereas the Kolmogoroff's microscale depends only on dissipative and viscous characteristics (Nezu and Nakagawa 1993). In order to identify the size of the Kolmogoroff's microscale $\eta$ (microeddies), the spectrum density function $S(\omega)$ is calculated for instantaneous, longitudinal velocities and next the proper frequency subrange of velocities is determined, and for that subrange the rate of energy dissipation $\varepsilon$ can be obtained (Kozioł 2012). The spectrum density function $S(\omega)$ expresses kinetic energy of eddies for the frequency range $(\omega, \omega+d \omega)$ and this function is not uniform versus fre- 
quency. This function takes the largest values for the frequencies of the averaged motion, while the lowest values are reached for the largest frequencies. The analysis of the spectrum density function involves, among others, the determination of the frequency subrange (inertial subrange), whose existence is assumed by the Kolmogoroff's hypothesis, and where the local anisotropy hypothesis is also valid as well as the " $-5 / 3$ " power law (Nikora 1999). Such a subrange is called the inertial subrange of a constant energy stream, coming from all scales of eddies: from the largest eddies to the smallest ones. The determination of the inertial subranges enables to find turbulence scales and energy dissipation rates. The aforementioned values can be calculated by applying following formulas (Nikora et al. 1994):

$$
\begin{gathered}
S(\omega)=C_{1} \varepsilon^{2 / 3} U^{2 / 3}(\omega)^{-5 / 3}, \\
\eta=\left(\frac{v^{3}}{\varepsilon}\right)^{1 / 4},
\end{gathered}
$$

where $C_{1}=0.48$ is a constant (Monin and Yaglom 1975), $\eta$ is the size of microeddies (Kolmogoroff's microscale), and $v$ is the molecular (kinematic) viscosity. Equations 3 and 4 are valid on the condition that the Taylor hypothesis of "frozen turbulence" is applied.

\section{EXPERIMENTAL SETUP AND PROCEDURE}

In this paper, an analysis of sizes of macro- and microeddies distributions in the channel, including all eight tests from two studies without and with the impact of floodplain trees, is presented (Fig. 1). Three measurements were conducted with the use of an electromagnetic meter (tests 1-3, Fig. 1a-c), and five measurements were continued with the use of the $10-\mathrm{MHz}$ acoustic Doppler velocity meter (ADV) (tests 4-5.1, Fig. 1d-e). Results of the first study (tests 1-3) were reported by Kozioł (2000) and Rowiński et al. (2002), while partial results of the second study were reported by Koziol (2008, 2012) (tests 4-5), Czernuszenko et al. (2007) (test 4), and Mazurczyk (2007) (test 5).

The experiments considered herein were carried out in the Hydraulic Laboratory of the Department of Hydraulic Engineering, Faculty of Civil and Environmental Engineering at the Warsaw University of Life Sciences SGGW. A straight open channel (16 m long and $2.10 \mathrm{~m}$ wide) with a symmetrically trapezoidal cross-section was used for the laboratory tests. The main channel width was $30 \mathrm{~cm}$ with a floodplain width of $60 \mathrm{~cm}$. The banks were inclined at a slope of 1:1. The channel bed slope of the channel was $0.5 \%$. Water discharge values were recorded with the use of the $540 \mathrm{~mm}$ diameter circular weir. A row of PCV pipes was installed in the upstream ap- 
a) Test 1

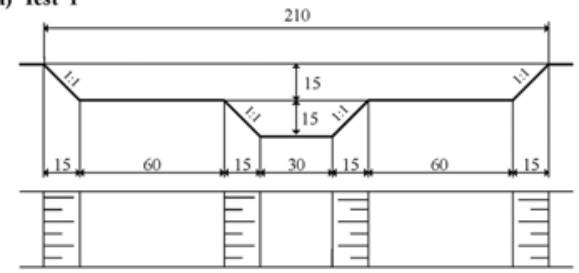

b) Test 2

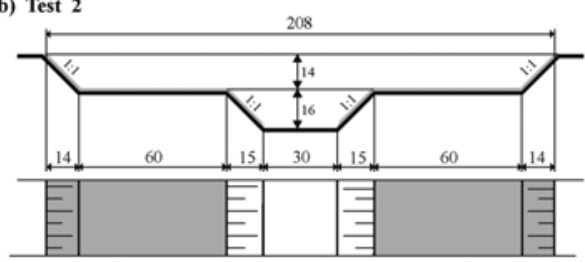

c) Test 3
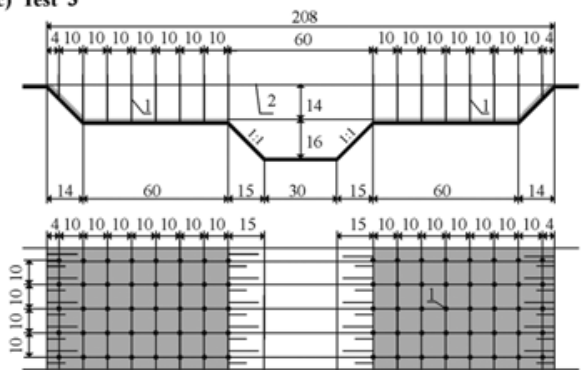

d) Tests $4,4.1$ and 4.2

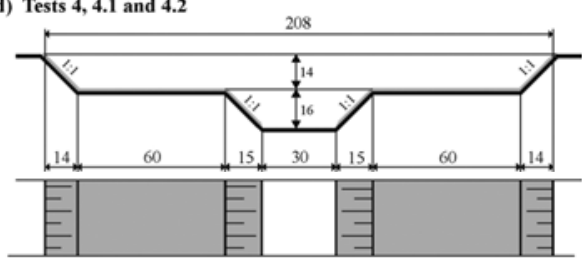

e) Test 5 and 5.1

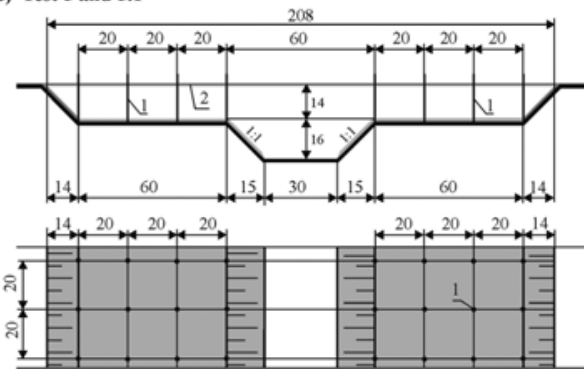

Fig. 1. Scheme of a laboratory cross-section for two considered studies. The first study: (a) test 1 in a channel with the smooth bed, (b) test 2 in a channel with the smooth bed of the main channel and rough floodplains, and (c) test 3 in a channel with the smooth bed of the main channel and rough floodplains vegetated with trees $(0.1 \times 0.1 \mathrm{~m}$ trees system). The second study: (d) tests $4,4.1$, and 4.2 in a channel with the smooth bed of the main channel and rough sloping banks of the main channel, rough floodplains, and (e) tests 5 and 5.1 in a channel with the smooth bed of the main channel and rough sloping banks of the main channel, rough floodplains vegetated with trees $(0.2 \times 0.2 \mathrm{~m}$ trees system). Explanations: $1-$ pipes imitating trees, and 2 - wooden strips supporting the trees (dimensions in $\mathrm{cm}$ ).

proach channel reach to straighten the flow. During the experiments the following parameters were measured: water levels in the main channel and on the floodplains, velocities, water temperature, and water discharge. Before general measurements were started, some trial velocity measurements had been performed in a few cross-sections at distances of 4 and $12 \mathrm{~m}$ from the channel entrance. These tests showed that the Reynolds number was sufficiently large, in order to create the state characterized by local isotropy and homogeneity and associated universal behaviour of statistical properties 
(e.g., velocity, standard deviation, and skewness). The cross-section half way down of the channel length was selected for velocity measurements. Instantaneous longitudinal velocities were measured with two probes.

In the first study, in tests 1,2 , and 3, instantaneous longitudinal velocities were measured with the use of the programmable electromagnetic liquid velocity meter manufactured by Delft Hydraulics. The accuracy of the measurement of velocity is $\pm 0.01 \mathrm{~m} / \mathrm{s}$. The measurements of instantaneous longitudinal velocities were carried out at 48 points at 10 verticals (verticals 6-36 and 39, Fig. 2). The time of velocity recording at each point was roughly $40 \mathrm{~min}$ with a sampling interval of $5 \mathrm{~Hz}$. The analysis of the velocity data showed that a sampling period slightly shorter than $27 \mathrm{~min}$ was enough to obtain fully steady statistical characteristics of the flow and, therefore, the time series of 8000 elements (corresponding to the time period of about $26.7 \mathrm{~min}$ ) were further elaborated. More detailed information about the methodology can be found in Rowiński et al. (2002).

In the second study, in tests 4, 4.1, 4.2, 5, and 5.1, instantaneous longitudinal velocities were measured with the use of a three-component acoustic Doppler velocity meter (ADV) manufactured by Sontek Inc. The ADV proved to yield a good description of the turbulence characteristics when certain conditions related to the flow itself and the configuration of the instrument were satisfied. The measurements were conducted with the maximum frequency of $25 \mathrm{~Hz}$ in the velocity range of 0 to $1.0 \mathrm{~m} / \mathrm{s}$ with an accuracy of $0.25 \mathrm{~cm} / \mathrm{s}$. The measurements of instantaneous velocities were carried out at 250 points at 23 verticals - six on each floodplain and eleven in the main channel (Fig. 2). The time of velocity recorded in several dozen points was roughly $20 \mathrm{~min}$; it turned out that a sampling time, slightly shorter than $6 \mathrm{~min}$, is enough to obtain fully steady statistical characteristics of the flow and, therefore, a time series of 9000 elements (corresponding to the time period of about $360 \mathrm{~s}$ ) has been used subsequently. More detailed information about the methodology can be found in the paper by Czernuszenko et al. (2007). Before the second study measurements were started, some trial velocity measurements had been performed by two probes in a few points in

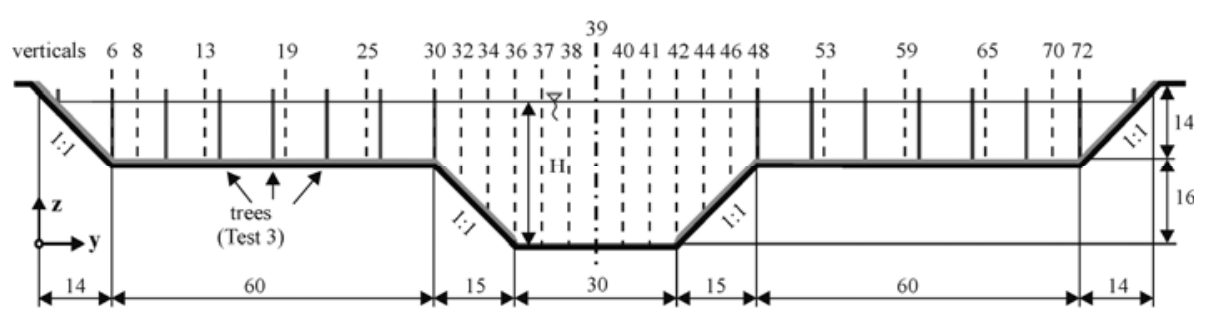

Fig. 2. Scheme of the experimental cross-section with the arrangement of measuring verticals (dimensions in $\mathrm{cm}$ ). 
the main channel and on the floodplains. The calculated values of velocity, standard deviations, skewness, and kurtosis coefficients were compared for two probes, and the comparison confirmed that the values obtained from the two instruments were similar.

In the first study, in test 1 , the surface of the channel bed was smooth (the smooth channel) and made of concrete. In tests 2 and 3 the floodplains were covered by cement mortar composed of terrazzo with grains of diameter within the range from 0.5 to $1 \mathrm{~cm}$. The values of an average Manning coefficient and absolute roughness of the channel surface were determined from the Manning's equation and the Colebrook-White's equation on the basis of the average velocity values of the flow measured in the main channel and on both the floodplains. For the smooth channel, Manning's roughness coefficient was equal to about $n=0.011 \mathrm{~m}^{-1 / 3} \mathrm{~s}, n=0.018 \mathrm{~m}^{-1 / 3} \mathrm{~s}$ for the left rough surface of the floodplain, and $0.025 \mathrm{~m}^{-1 / 3} \mathrm{~s}$ for the right surface. The obtained roughness amounted to $k_{s}=0.00005 \mathrm{~m}$ for the smooth surfaces, $k_{s}=0.0074 \mathrm{~m}$ for the rough surface of the left floodplain, and $k_{s}=0.0124 \mathrm{~m}$ for the rough surface of the right floodplain. In test 3, rigid emergent stems of riparian trees growing on the floodplains were modelled by aluminium pipes of $0.8 \mathrm{~cm}$ diameter, placed with both longitudinal and lateral spacings of $10 \mathrm{~cm}\left(100\right.$ stems per $\mathrm{m}^{2}$, Fig. 1c). The type of arrangement of stems is illustrated in Fig. 1. The stems simulate basically only the rigid stem of trees. There were 16 pipes in each of 161 cross-sections.

In the second study (tests 4, 4.1, 4.2, 5, and 5.1), both banks of the main channel were covered by cement mortar composed with terrazzo with grains of diameter within the range 0.5 to $1 \mathrm{~cm}$ (Fig. 1d-e). In tests 5 and 5.1 rigid emergent stems of riparian trees growing on the floodplains were modelled

Table 1

The hydraulic parameters

\begin{tabular}{|c|c|c|c|c|c|c|c|c|}
\hline \multirow{2}{*}{ Parameter } & \multicolumn{8}{|c|}{ Test } \\
\hline & 1 & 2 & 3 & 4 & 4.1 & 4.2 & 5 & 5.1 \\
\hline Discharge $Q[1 / \mathrm{s}]$ & 69.3 & 50.0 & 38.9 & 95.2 & 81.1 & 61.5 & 65.7 & 58.9 \\
\hline Depth in the main channel $H[\mathrm{~cm}]$ & 20.2 & 21.9 & 21.2 & 28.3 & 26.4 & 24.1 & 28.0 & 26.3 \\
\hline Depth on the floodplain $h_{f}[\mathrm{~cm}]$ & 5.2 & 5.9 & 5.2 & 12.3 & 10.4 & 8.1 & 12.0 & 10.3 \\
\hline Relative depth $D r=h_{f} / H$ & 0.26 & 0.27 & 0.24 & 0.43 & 0.39 & 0.34 & 0.43 & 0.39 \\
\hline Vegetation on the floodplains & - & - & Trees & - & - & - & $\operatorname{Tr}$ & ees \\
\hline The sloping banks $[-]$ & \multicolumn{8}{|c|}{$1: 1$} \\
\hline The bed slope $i[\%$ ] & \multicolumn{8}{|c|}{0.5} \\
\hline
\end{tabular}


by aluminium pipes of $0.8 \mathrm{~cm}$ diameter, placed with both longitudinal and lateral spacings of $20 \mathrm{~cm}\left(25\right.$ stems per $\mathrm{m}^{2}$, Fig. 1e). There were 8 stems in tests 5 and 5.1 in 80 cross-sections. The hydraulic parameters of two studies are given in Table 1 .

\section{RESULTS AND ANALYSIS}

\subsection{Temporal scale of macroeddies in the stream}

The ranges of the calculated values of time macroscales on the floodplains and in the main channel for all analysed tests are given in Table 2. The calculated Euler time-macroscale values ranged from 0.08 to $0.95 \mathrm{~s}$ on the floodplains without trees, while in the main channel they varied from 0.08 to $1.97 \mathrm{~s}$ (Table 2). On the other hand, in scenarios with floodplain trees, the time-macroscale values ranged from 0.1 to $0.98 \mathrm{~s}$ on the floodplains, while in the main channel they ranged from 0.1 to $0.82 \mathrm{~s}$ (Table 2). In the main channel the largest values of time-macroscale were reached for a smooth bed (test 1), and the lowest were found for tests 5 and 5.1. Introducing rigid, emergent vegetation causes generation of wakes behind each stem; therefore, trees generated a decrease of time-macroscale in test 5 , in comparison with test 4 , both for the main channel and the floodplains.

Table 2

The calculated values of the macro time-scale of turbulence $T_{E}$ [s]

\begin{tabular}{|l|c|c|c|c|}
\hline \multicolumn{1}{|c|}{ Area } & Test 1 & Test 2 & Test 3 (trees) & Test 4 \\
\hline The left floodplains & $0.15-0.62$ & $0.25-0.95$ & $0.30-0.98$ & $0.14-0.59$ \\
The main channel & $0.10-1.97$ & $0.23-0.76$ & $0.50-0.82$ & $0.15-0.96$ \\
The right floodplains & - & - & - & $0.13-0.62$ \\
\hline \multicolumn{1}{|c|}{ Area } & Test 4.1 & Test 4.2 & Test 5 (trees) & Test 5.1 (trees) \\
\hline The left floodplains & $0.09-0.74$ & $0.15-0.68$ & $0.10-0.51$ & $0.14-0.38$ \\
The main channel & $0.08-0.63$ & $0.07-0.64$ & $0.10-0.46$ & $0.10-0.50$ \\
The right floodplains & $0.08-0.65$ & $0.08-0.58$ & $0.14-0.42$ & $0.18-0.38$ \\
\hline
\end{tabular}

\subsection{Spatial longitudinal scales of macroeddies in the stream}

The calculated mean longitudinal sizes of macroeddies and relative sizes of macroeddies $(L / h)$ related to the water depths $h$ at location of $y$ (Fig. 2) are presented in Table 3.

Figure 3 illustrates the contour lines for the longitudinal relative sizes of macroeddies $(L / h)$. The results show that for all tests with rough floodplains, the relative sizes of macroeddies are larger on the floodplains than in the main channel. The largest sizes appear on the floodplains in the interaction 
Table 3

The calculated longitudinal sizes of macroeddies $L$ (spatial macro-scale)

\begin{tabular}{|l|c|c|c|c|c|c|c|c|c|}
\hline \multirow{2}{*}{ Area } & \multicolumn{2}{|c|}{ Test 1} & \multicolumn{2}{c|}{ Test 2} & \multicolumn{2}{c|}{ Test 3 (trees) } & \multicolumn{2}{c|}{ Test 4} \\
\cline { 2 - 10 } & $L[\mathrm{~cm}]$ & $L / h$ & $L[\mathrm{~cm}]$ & $L / h$ & $L[\mathrm{~cm}]$ & $L / h$ & $L[\mathrm{~cm}]$ & $L / h$ \\
\hline The left floodplains & $6-24$ & $1.1-4.2$ & $3-17$ & $0.5-2.9$ & $2-11$ & $0.4-2.1$ & $4-19$ & $0.3-1.6$ \\
The main channel & $4-89$ & $0.2-4.4$ & $8-30$ & $0.4-1.6$ & $13-25$ & $0.6-1.7$ & $3-26$ & $0.1-1.2$ \\
The right flood plains & - & - & - & - & - & - & $1-23$ & $0.1-1.2$ \\
\hline \multirow{4}{*}{ Area } & \multicolumn{3}{|c|}{ Test 4.1} & \multicolumn{2}{c|}{ Test 4.2 } & Test 5 (trees) & Test 5.1 (trees) \\
\cline { 2 - 10 } & $L[\mathrm{~cm}]$ & $L / h$ & $L[\mathrm{~cm}]$ & $L / h$ & $L[\mathrm{~cm}]$ & $L / h$ & $L[\mathrm{~cm}]$ & $L / h$ \\
\hline The left floodplains & $2-24$ & $0.2-2.3$ & $4-20$ & $0.5-2.5$ & $2-9$ & $0.2-0.8$ & $1-8$ & $0.1-0.8$ \\
The main channel & $2-21$ & $0.1-1.2$ & $2-17$ & $0.1-1.0$ & $1-13$ & $0.2-0.7$ & $1-15$ & $0.1-0.8$ \\
The right floodplains & $2-24$ & $0.1-2.3$ & $2-13$ & $0.2-1.6$ & $2-9$ & $0.2-0.8$ & $1-8$ & $0.1-0.7$ \\
\hline
\end{tabular}

zone, close to the main channel, and the smallest ones occur over the main channel bed.

Figure 4 illustrates the changes of relative sizes of macroeddies $(L / h)$ as a function of the relative depth $z / h$ ( $z$ is the distance from the bed), at selected measurement verticals on the floodplains and in the main channel. The distributions of longitudinal sizes of macroeddies in verticals are not similar within the whole channel cross-section.

\section{Macroeddies in the main channel}

For the smooth channel (test 1) the largest relative sizes of macroeddies were achieved for the main channel centreline (V39, Fig. 4), and the smallest size was reached in test 4 , with the rough surface of main channel sloping banks and floodplains (Fig. 4) (Kozioł 2000). In the main channel in test 1, when for a relative depth of $z / h=0.5$, the largest relative sizes of macroeddies were equal to 4.4 times the stream depth (V39, Fig. 4). The increase of the roughness of the floodplains (test 2) and the main channel sloping banks (tests 4-4.2) resulted in a decrease of water velocity and also reduced the sizes of macroeddies. The increase of roughness on the floodplains in test 2 resulted in the decrease in sizes of macroeddies at the bed and at the water surface only, but in the middle depth zone $(0.25<z / h<0.75$, V39, Fig. 4) it almost did not change and amounted to about one time stream depth. However, the increase of main channel sloping banks roughness in tests 4-4.2 resulted in the decrease in sizes of macroeddies in the main channel to 0.5 of the stream depth (V39, Fig. 4). Floodplain trees (tests 3, 5, and 5.1) resulted in the decrease of water velocities in the main channel, which are identical in verticals for three tests (V39, Fig. 4); however, sizes of macroeddies almost did not change in the smooth main channel (tests 2-3, Fig. 3, V39 in Fig. 4), 

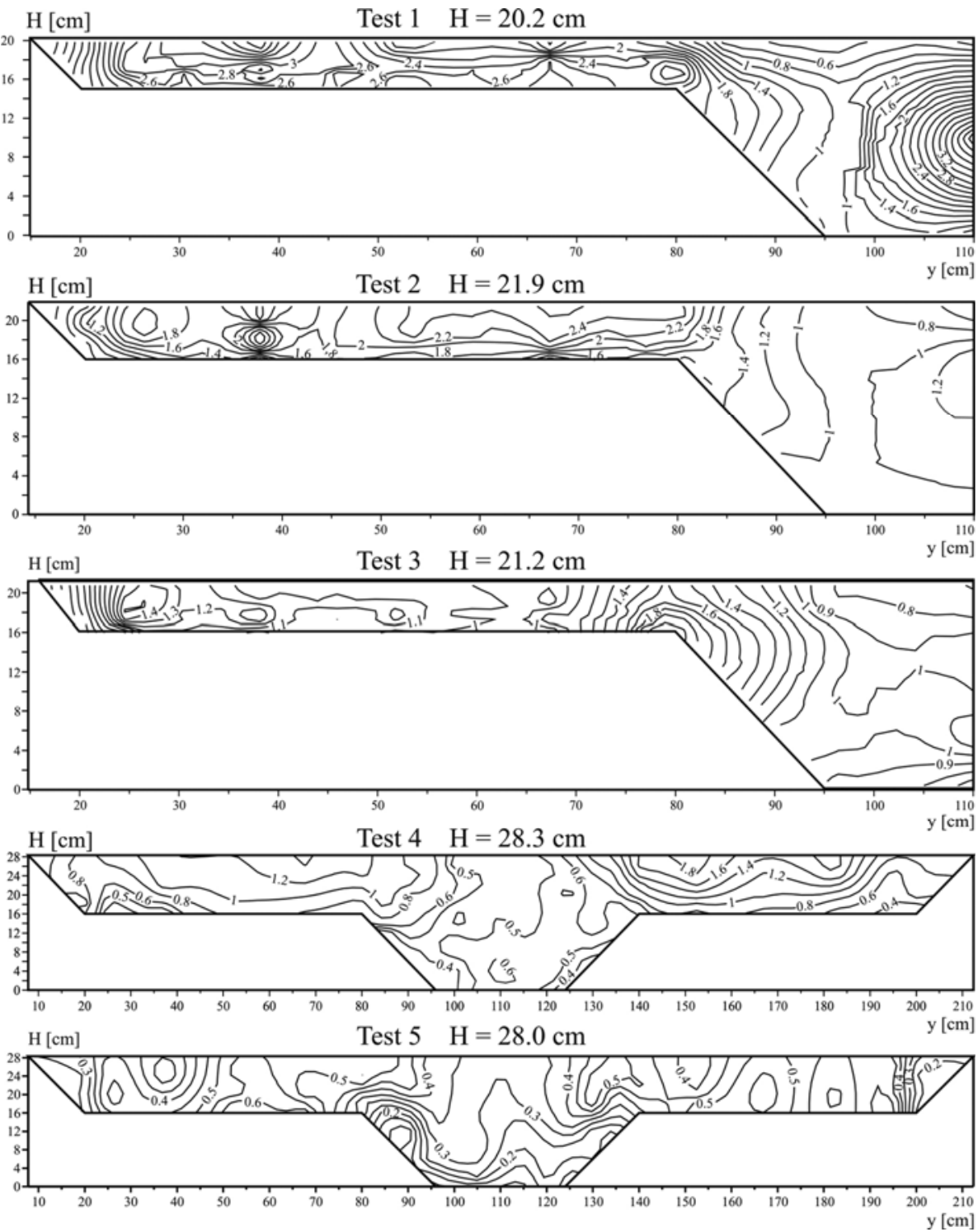

Fig. 3. Contour lines for longitudinal relative sizes of macroeddies $(L / h)$.

but they decreased from $L / h=0.6$ (test 4) to 0.3 (test 5) in the main channel with rough banks. The comparison of the main channel to rough banks (tests 5 and 5.1) shows that sizes of macroeddies are over three times larger in the smooth main channel (test 3, Fig. 3, V39 in Fig. 4). 

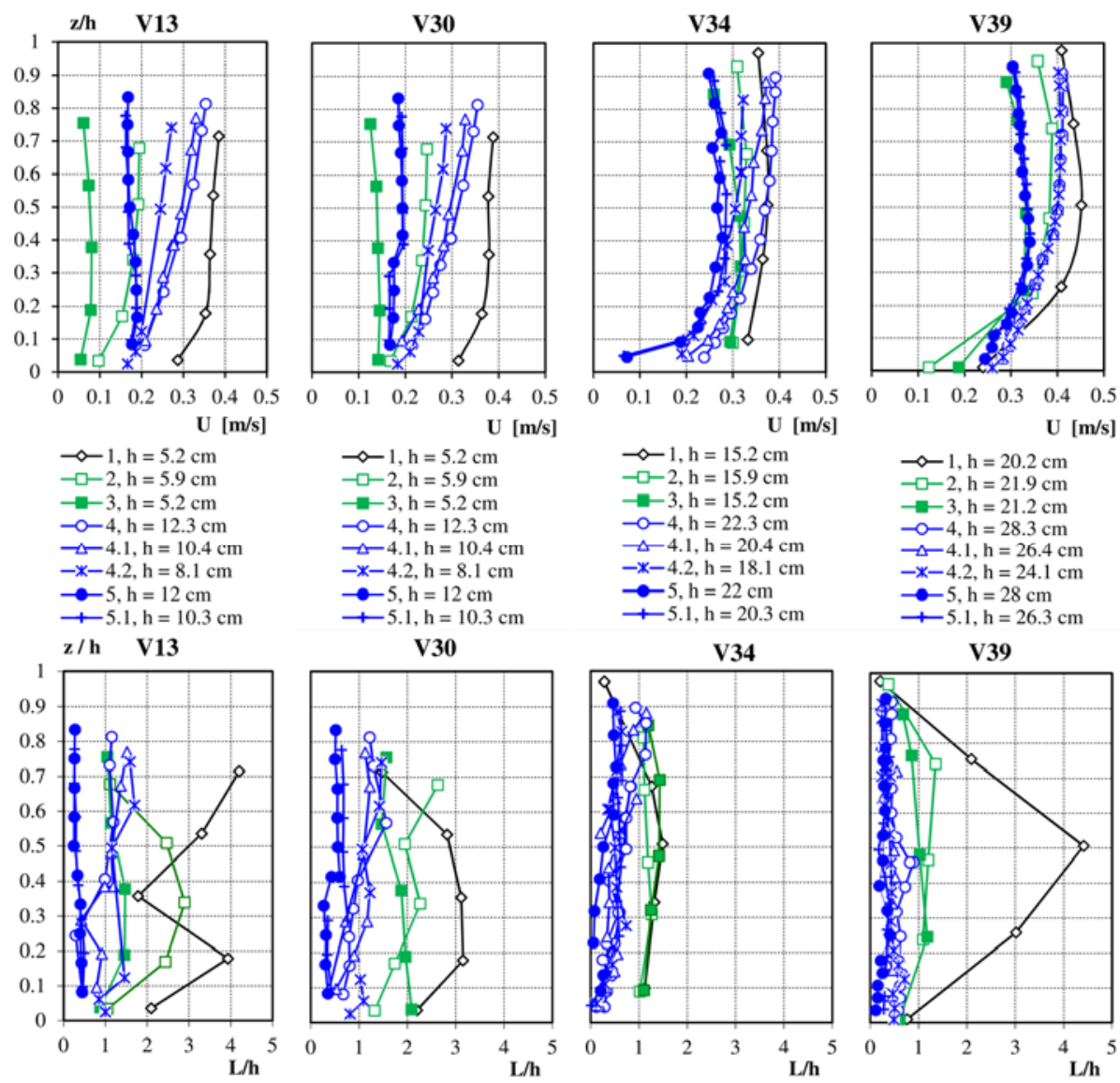
$\mathrm{h}=21.9 \mathrm{~cm}$ $-3, \mathrm{~h}=21.2 \mathrm{~cm}$ $-0-4, \mathrm{~h}=28.3 \mathrm{~cm}$ $-\triangle 4.1, \mathrm{~h}=26.4 \mathrm{~cm}$ $-*-4.2, \mathrm{~h}=24.1 \mathrm{~cm}$ $\longrightarrow 5, \mathrm{~h}=28 \mathrm{~cm}$
$+5.1, \mathrm{~h}=26.3 \mathrm{~cm}$

V34

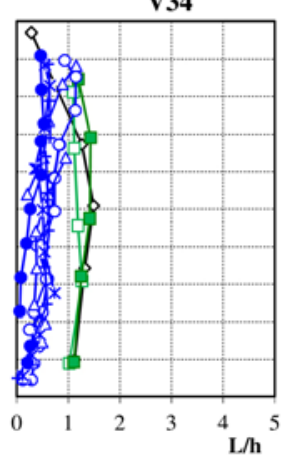
V39

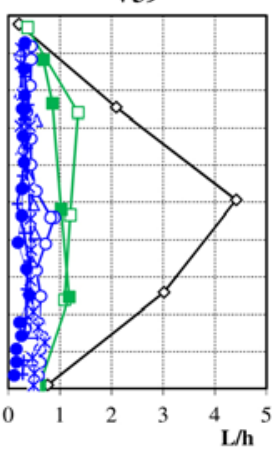

Fig. 4. Example vertical distributions of longitudinal velocities and relative sizes of macroeddies on floodplains.

\section{Macroeddies over the sloping banks of the main channel}

The sizes of macroeddies are the largest nearby the floodplain over the sloping banks of the main channel (Fig. 3, V30 in Fig. 4) and the smallest in the vertical located between the sloping bank and the main channel (Fig. 3). In the vertical located between the sloping bank and the bed of the main channel, the largest sizes of macroeddies occur in the smooth channel (test 1) and in the channel with rough floodplains (test 2), and the sizes are of the order of the stream depth (Fig. 3). The smallest sizes of macroeddies appeared in the channel with rough floodplains and rough sloping banks (tests 4-4.2), and they decreased downwards, towards the bed, from 1 to 0.1 times the stream depth (Fig. 3, V34 in Fig. 4). Over the sloping banks of the main channel close to the floodplains, where the greatest interaction between the 
main channel and the floodplain exists, the largest sizes of macroeddies appear only in the smooth channel (test 1), and at the bed they reach 2 stream depths (Fig. 3, V30 in Fig. 4). The smallest sizes of macroeddies occur in the case of rough floodplains and rough sloping banks of the main channel (tests 4-4.2), and here the size decreases downwards the bed from 1.2 to 0.1 times the stream depth (Fig. 3, V30 in Fig. 4). In the smooth channel, sizes of macroeddies increase downwards the bed, and in the channel with rough floodplains they remain constant with depth $(L / h=1.5$ approximately). Floodplain trees (tests 3,5, and 5.1) resulted in a decrease of water velocity over smooth sloping banks of the main channel only above $z / h=0.4$, but over the rough sloping banks the velocity decreased in the whole depth (V34, Fig. 4). Sizes of macroeddies are the largest over the sloping banks of the main channel, close to the floodplain in case when the sloping banks are smooth (test 3). The farther from the floodplains, the smaller the impact of trees on sizes of macroeddies over the main channel sloping banks.

\section{Macroeddies on the floodplains}

On the floodplains, the largest relative sizes of macroeddies were achieved in the smooth channel, and reached 4 times the stream depth (Table 3, Fig. 4). The increase of the roughness of floodplains and the main channel sloping banks resulted in the lowest sizes of macroeddies in tests 4-4.2, which appear in a vertical near the bed and close to the sloping bank of the floodplain. The largest, relative sizes of macroeddies on the floodplain are observed at the floodplain/main channel interface. On both floodplains, sizes of macroeddies decreased downwards the bed, from 2.5 to 0.1 times the stream depth; however, close to the floodplain sloping banks the macroeddies were almost constant with depth, and are equal to one stream depth.

Trees on the floodplains (tests 3, 5, and 5.1; Fig. 4) resulted in the relative scales of macroeddies' values being more uniform. It is clear that the emergent vegetation generates turbulence along all verticals by creation of a wake behind a row of parallel rods. In other words, some large local gradients of a mean velocity exist behind the "trees", thereby making the relative scales of macroeddies much smaller and the vertical distributions of macroeddies more uniform. In tests 5 and 5.1 on both floodplains, relative sizes of macroeddies are lower than one time the stream depth, ranging from 0.1 to 0.8 of the stream depth. In some verticals, almost behind a tree, relative sizes of macroeddies slightly increase downwards the bed (V13, Fig. 4).

In tests 3,5 , and 5.1, relative sizes of macroeddies were slightly different close to the floodplain sloping bank only, but in other areas of the channel cross-section, the macroeddies were several times larger in test 3 than in other cases. Lower relative sizes of macroeddies in tests 5 and 5.1 were achieved for rough main channel sloping banks and the two times smaller 
number of floodplain trees. It can be concluded that a more significant influence on the decreasing macroeddies' size is exerted by an increasing roughness of the main channel than by 2 times smaller density of floodplain trees.

Additional proof for this can be found in research by Nepf and Vivoni (2000), Carollo et al. (2005), and Mazurczyk (2007). Carollo et al. (2005) found that the increase of an absolute roughness resulted in a decrease in longitudinal macroeddies size. These findings were based on the gravelbottom channels research, considering a different grain size. However, Nepf and Vivoni (2000) and also Mazurczyk (2007) performed research on channels with emergent vegetation and proved that the increase of vegetation density considerably decreases sizes of macroeddies, so the decrease of the density should lead to an increase of the macroeddies size. A literature review of laboratory and field measurement results (e.g., McQuivey et al. 1971, Nikora et al. 1994, Nikora and Smart 1997, Mazurczyk 2007) proved that sizes of macroeddies usually ranged from 0.5 to 4 times the stream depth, so the results achieved in this paper are consistent with the research results by other authors.

\subsection{Spatial longitudinal scales of microeddies in the stream}

The analysis of the spectrum density function enabled us to determine an inertial subrange and the subsequent determination of the energy dissipation rates (Eq. 3), and the sizes of Kolmogorov's microeddies $\eta$ (Eq. 4) were calculated. Figure 5 presents the frequency spectra $S(f)$ of instantaneous longitudinal velocities in analysed tests. The presence of floodplain trees resulted in the decrease of values of the spectrum density function (e.g., comparing test 2 and 4 or 4 and 5, Fig. 5).

Figure 6 presents vertical distribution of longitudinal velocities and longitudinal sizes of microeddies in tests 1,2 , and 4 for non-vegetated floodplains. The calculated values of microeddies are very small in comparison with the value of velocity (Fig. 6) and with the sizes of macroeddies $L$ which most often are presented in relation to the water depth (Fig. 4). All calculated sizes of microeddies are in the order of decimal parts of a millimetre, and they vary from 0.13 to $0.44 \mathrm{~mm}$. Most of calculated values do not vary significantly in the channel, and they are approximately $0.2 \mathrm{~mm}$, while the increase of sloping banks roughness in the main channel resulted in a growth of microeddies size in the main channel that they reached, from 0.24 to $0.44 \mathrm{~mm}$ in length (test $4, \mathrm{~V} 39$, Fig. 6b). It was concluded that the increase of the floodplain roughness and main channel sloping banks roughness did not result in vital changes of the microeddies size on the floodplain. However, the increase of floodplain roughness and the increase of the main channel sloping banks roughness resulted in a growth of microeddies size in the main channel (Fig. 6b). 

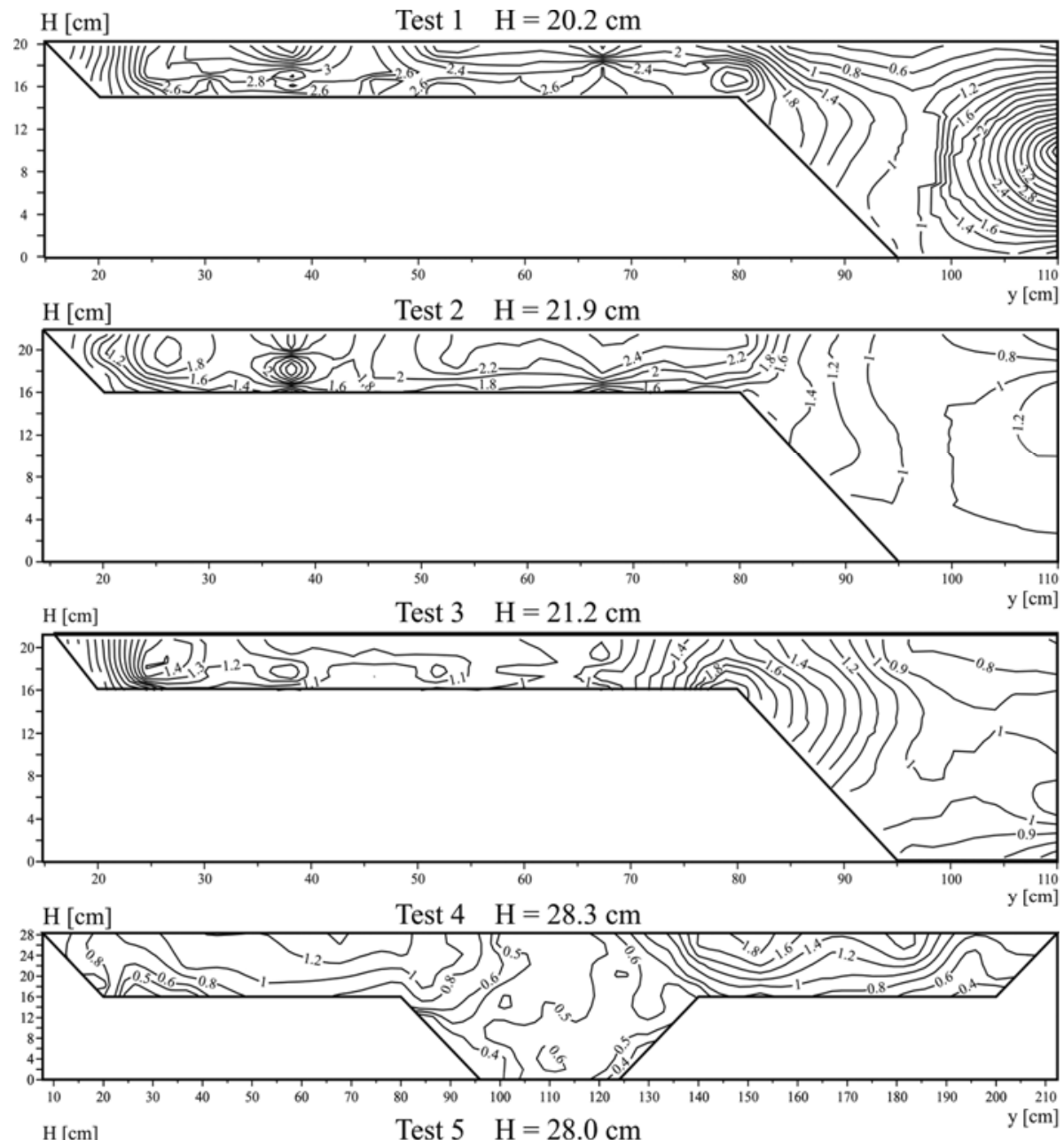

Fig. 5. Frequency spectra $S(f)$ of instantaneous longitudinal velocities in tests 1-5 ( $z$ is the distance from the bed).

Figure 7 presents vertical distributions of longitudinal velocities and sizes of Kolmogoroff's microeddies $\eta$ in the compound channel with emergent vegetation on the floodplains (tests 3 and 5). Trees did not result in large changes of sizes of microeddies, and the calculated values are also very simi- 


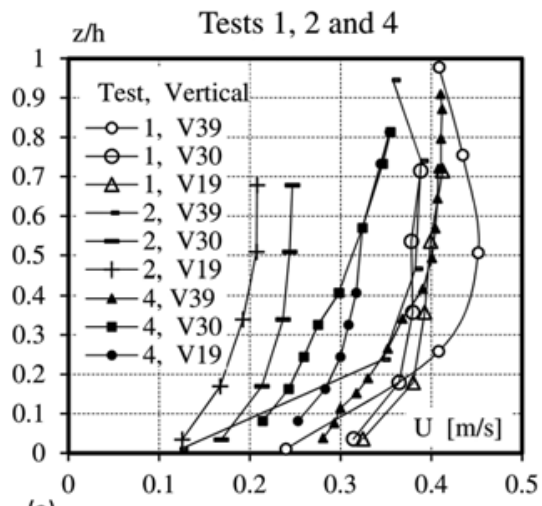

(a)
Tests 1, 2 and 4

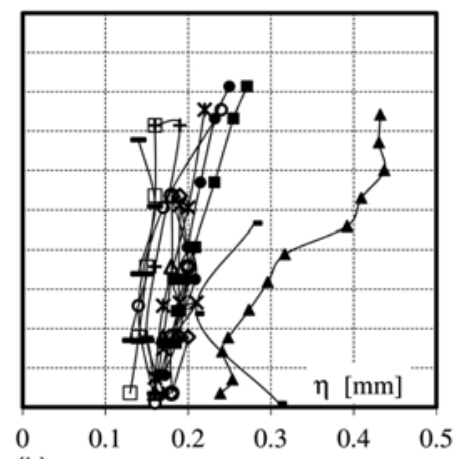

(b)
Test, Vertical

-o- 1, V39

* $1, \quad$ V36

$x-1, \quad \mathrm{~V} 32$

- $-1, \quad$ V30

$\diamond 1, \quad \mathrm{~V} 25$

$\triangle 1, \quad$ V19

- $1, \quad \mathrm{~V} 8$

- 2, V39

- 2, V30

+2 , V19

$\leftarrow$ 4, V39

$\rightarrow-4, \quad$ V30

$\longrightarrow 4, \quad$ V19

Fig. 6. Vertical distribution of longitudinal velocities and sizes of microeddies in tests 1,2 , and 4 .

$\mathrm{z} / \mathrm{h} \quad$ Tests 1,2 and 3

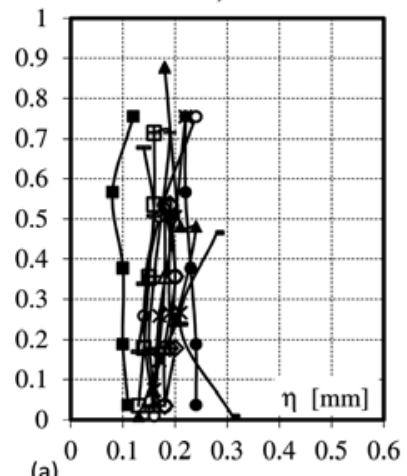

Test, Vertical

$\begin{array}{ll}\longrightarrow-1, & \text { V39 } \\ \rightarrow-1, & \text { V36 }\end{array}$

$\rightarrow \begin{array}{lll}*-1, & \mathrm{~V} 32 \\ -1, & \mathrm{~V} 30\end{array}$

$\diamond 1, \quad \mathrm{~V} 25$

$\triangle 1, \quad$ V19

七- $1, \quad \mathrm{~V} 8$

$-2, \quad$ v39

-2 , V30

十 2, V19

$\rightarrow 3, \quad$ V39

$\rightarrow-3, \quad \mathrm{v} 30$

$\rightarrow 3, \quad$ V19

(a)

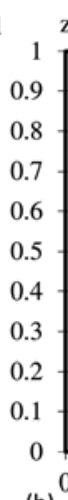

(b)

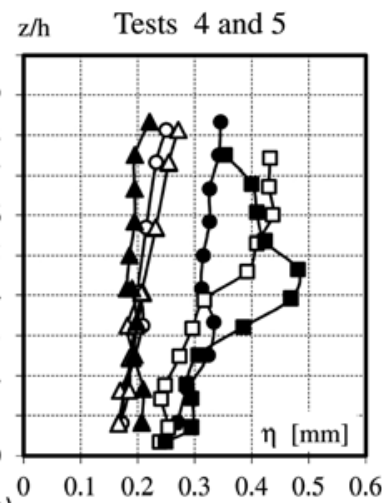

Test, Vertical

$-0-4, \quad$ V19

$\rightarrow-5, \quad$ V19

$\triangle-4, \quad$ V30

$\rightarrow 5, \quad \mathrm{~V} 30$

$\rightarrow-4, \quad$ V39

$\rightarrow-5, \quad$ V39

Fig. 7. Distribution of longitudinal sizes of microeddies in tests 1-5.

lar and range from 0.08 to $0.48 \mathrm{~mm}$. In test 3 , the sizes of microeddies did not change on the floodplain and in the main channel, but only in the interaction zone, close to the surface that divides the main channel and the floodplain, the eddies disintegrated into structures of smaller sizes (V30, Fig. 7a). In test 5, floodplain trees contributed to the disintegration into structures of bigger sizes on the floodplain, bigger by about $50 \%$ in comparison with test 3 , but had no influence on the vertical distribution of sizes of microeddies (V19, Fig. 7b). However, in the plane dividing the main channel and the floodplain, the sizes of microeddies did not vary considerably, and in the test with floodplain trees, the sizes of microeddies did not change with depth (V30, Fig. 7b). Therefore, the sizes of microeddies are slightly bigger near the bed and smaller above the relative depth $z / h=0.4$ in test 5 . In the main channel the sizes of microeddies almost did not change in test 5 , but flood- 
plain trees resulted in changes of the vertical distribution of microeddies size (V39, Fig. 7b). The longest sizes of microeddies are at the relative depth $z / h=0.45$. The sizes of microeddies are significantly bigger in the middle zone of the main channel $(z / h=0.3-0.7)$ than on the floodplain.

Trees on the floodplains did not lead to considerable changes of sizes of microeddies, and usually their values were very similar. The analysed microscale was within the range from 0.1 to $10 \mathrm{~mm}$. This statement is consistent with the results achieved for free streams and near the wall regions (Czernuszenko and Lebiecki 1989, Nikora et al. 1994, Nikora and Smart 1997, Mazurczyk 2007).

\section{CONCLUSIONS}

Investigations of the longitudinal sizes of macro- and microeddies, presented in the paper, are based on measurements of instantaneous velocities in a hydraulic laboratory in a compound trapezoidal channel with different roughness conditions (smooth bed, rough bed) and with a trees system on the floodplains. The increase of a channel bottom roughness resulted in a considerable decrease in longitudinal sizes of macroeddies in the whole channel. In case of rough floodplains and rough sloping banks of the main channel, sizes of macroeddies become larger on the floodplains than in the main channel; in verticals the size increased upwards the water surface on the floodplains and over the main channel sloping banks, but over the bed of the main channel it was almost constant with depth. In all tests with and without floodplain trees, the largest macroeddies appeared on the floodplain/main channel interface, and the lowest were found over the main channel bed. Floodplain trees resulted in a decrease in water velocity and sizes of macroeddies; the most significant decrease took place on the floodplains, and the less significant concerns the main channel. Trees located in the active flow zone on the floodplains resulted in macroeddies disintegrating and significant decreasing their size, but also contributed to their constant value versus depth. However, trees did not influence the values and vertical distribution of macroeddies over the main channel bed. More significant influence on sizes of macroeddies decreasing in the whole channel is exerted by the increase of the main channel sloping banks roughness than the influence of twice decreased density of floodplain trees.

The calculated values of sizes of microeddies varied within the ranges of 0.08 to $0.48 \mathrm{~mm}$. The changes of longitudinal sizes of microeddies on the floodplains were not influenced by the increase of floodplain roughness (test 2), the increase of main channel sloping banks roughness (test 4), or the presence of trees, but only for the smooth main channel (test 3 ). However, when the roughness of the floodplains and sloping banks of the main channel 
were identical (test 5), the occurrence of trees resulted in disintegration of the sizes of macroeddies into bigger sizes of microeddies. The increase of the main channel sloping banks roughness (test 4) and the occurrence of trees (test 5) resulted in an increase of sizes of the microeddies in the main channel. The sizes of the microeddies are greater in the centreline of the main channel than on the floodplains, the smallest being in the main channel/floodplain interface. The calculated longitudinal sizes of microeddies were very small in comparison to the value of velocity $(0.05-0.45 \mathrm{~m} / \mathrm{s})$ and to the scale of macroeddies which most often are presented in relation to the water depth. The values of the microeddies were in the order of decimal parts of a millimetre, and that is why it is difficult to draw conclusions about significant changes of their values as a result of an influence of bed roughness and floodplain trees.

\section{References}

Ben Meftah, M., F. De Serio, D. Malcangio, and A.F. Petrillo (2006), Experimental study of flexible and rigid vegetation in an open channel. In: Proc. Int. Conf. on Fluvial Hydraulics "River Flow 2006”, 6-8 September 2006, Lisbon, Portugal, 603-611.

Carollo, F.G., V. Ferro, and D. Termini (2005), Analyzing turbulence intensity in gravel bed channels, J. Hydraul. Eng. ASCE 131, 12, 1050-1061, DOI: 10.1061/(ASCE)0733-9429(2005)131:12(1050).

Czernuszenko, W., and P. Lebiecki (1989), The turbulence in river-flows, Arch. Hydrotech. 36, 1-2, 17-34 (in Polish).

Czernuszenko, W., A. Kozioł, and P.M. Rowiński (2007), Measurements of 3D turbulence structure in a compound channel, Arch. Hydro-Eng. Environ. Mech. 54, 1, 55-73.

Knight, D.W., and K. Shiono (1990), Turbulence measurements in a shear layer region of a compound channel, J. Hydraul. Res. 28, 2, 175-195, DOI: 10.1080/00221689009499085.

Knight, D.W., and K. Shiono (1996), River channel and floodplain hydraulics. In: M.G. Anderson, D.E. Walling, and P.D. Bates (eds.), Floodplain Processes, Ch. 5, John Wiley and Sons, Chichester, 139-181.

Knight, D.W., K.W.H. Yuen, and A.A.I. Alhamid (1994), Boundary shear stress distributions in open channel flow. In: K. Beven, P. Chatwin, and J. Millbank (eds.), Physical Mechanisms of Mixing and Transport in the Environment, John Wiley and Sons, New York, 51-87.

Kozioł, A.P. (2000), Longitudinal sizes of the largest eddies in the compound channel, Prz. Nauk. Wydz. Inż. Ksztalt. Środow. 18, 151-159 (in Polish). 
Kozioł, A.P. (2008), Investigation of the time and spatial macro-scale of turbulence in a compound channel, Acta Sci. Pol. - Architectura 7, 4, 15-23 (in Polish).

Kozioł, A.P. (2012), The Kolmogorov's microscale eddies in a compound channel, Ann. Warsaw Univ. Life Sci. - SGGW, Land Reclamation 44, 2, 121-132, DOI: $10.2478 / \mathrm{v} 10060-011-0068-7$.

Kozioł, A.P. (2013), Three-dimensional turbulence intensity in a compound channel, J. Hydraul. Eng. 139, 8, 852-864, DOI: 10.1061/(ASCE)HY.1943-7900. 0000739.

Kubrak, E., J. Kubrak, and P.M. Rowiński (2013), Application of one-dimensional model to calculate water velocity distributions over elastic elements simulating Canadian waterweed plants (Elodea Canadensis), Acta Geophys. 61, 1, 194-210, DOI: 10.2478/s11600-012-0051-7.

Mazurczyk, A. (2007), Scales of turbulence in compound channels with trees on floodplains, Publs. Inst. Geophys. Pol. Acad. Sc. E-7, 401, 169-176.

McQuivey, R.S., T.N. Keefer, and M.A. Shirazi (1971), Basic data report on the turbulent spread of heat and matter, Open-file Report, USA Dept. of Interior Geological Survey, Fort Collins, USA, 166 pp.

Monin, A.S., and A.M. Yaglom (1975), Statistical Fluid Mechanics: Mechanics of Turbulence, Vol. 2, MIT Press, Cambridge.

Nepf, H., and M. Ghisalberti (2008), Flow and transport in channels with submerged vegetation, Acta Geophys. 56, 3, 753-777, DOI: 10.2478/s11600-008-0017-y.

Nepf, H.M., and E.R. Vivoni (2000), Flow structure in depth-limited, vegetated flow, J. Geophys. Res. 105, C12, 28547-28557, DOI: 10.1029/2000JC 900145.

Nezu, I., and H. Nakagawa (1993), Turbulence in Open-Channel Flows, IAHR Monographs, Balkema, Rotterdam, 293 pp.

Nikora, V.I. (1999), Origin of the " -1 " spectral law in wall-bounded turbulence, Phys. Rev. Lett. 83, 4, 734-736, DOI: 10.1103/PhysRevLett.83.734.

Nikora, V.I., and G.M. Smart (1997), Turbulence characteristics of New Zealand gravel-bed rivers, J. Hydraul. Eng. 123, 9, 764-773, DOI: 10.1061/(ASCE) 0733-9429(1997)123:9(764).

Nikora, V.I., P. Rowiński, A. Sukhodolov, and D. Krasuski (1994), Structure of river turbulence behind warm-water discharge, J. Hydraul. Eng. 120, 2, 191-208, DOI: 10.1061/(ASCE)0733-9429(1994)120:2(191).

Rowiński, P.M., and A. Mazurczyk (2006), Turbulent characteristics of flows through emergent vegetation. In: Proc. Int. Conf. on Fluvial Hydraulics "River Flow 2006”, 6-8 September 2006, Lisbon, Portugal, 623-630.

Rowiński, P.M., W. Czernuszenko, A.P. Kozioł, and J. Kubrak (2002), Properties of a streamwise turbulent flow field in an open two-stage channel, Arch. Hydro-Eng. Environ. Mech. 49, 2, 37-57. 
Sanjou, M., I. Nezu, S. Suzuki, and K. Itai (2010), Turbulence structure of compound open-channel flows with one-line emergent vegetation, In: $J$. Hydrodyn. B 22, 5, Suppl. 1, 577-581, DOI: 10.1016/S1001-6058(09)60255-9.

Shiono, K., and D.W. Knight (1990), Mathematical models of flow in two or multi stage straight channels. In: Proc. Int. Conf. on River Flood Hydraulics, Wallingford, United Kingdom, 229-238.

Shiono, K., and D.W. Knight (1991), Turbulent open-channel flows with variable depth across the channel, J. Fluid Mech. 222, 7, 617-646, DOI: 10.1017/ S0022112091001246.

Siniscalchi, F., V.I. Nikora, and J. Aberle (2012), Plant patch hydrodynamics in streams: Mean flow, turbulence, and drag forces, Water Resour. Res. 48, 1, W01513, DOI: 10.1029/2011WR011050.

Terrier, B., S. Robinson, K. Shiono, A. Paquier, and T. Ishigaki (2010), Influence of vegetation to boundary shear stress in open channel for overbank flow. In: Dittrich, Koll, Aberle, and Geisenhainer (eds.), Proc. Int. Conf. River Flow 2010, Bruansweig, Germany, Vol. 1, 285-292.

Tominaga, A., I. Nezu, K. Ezaki, and H. Nakagawa (1989), Three-dimensional turbulent structure in straight open channel flows, J. Hydraul. Res. 27, 1, 149173, DOI: $10.1080 / 00221688909499249$.

Yang, K., S. Cao, and D.W. Knight (2007), Flow patterns in compound channels with vegetated floodplains, J. Hydraul. Eng. 133, 2, 148-159, DOI: 10.1061/(ASCE)0733-9429(2007)133:2(148).

Received 22 April 2013

Received in revised form 20 June 2014

Accepted 23 June 2014 